\title{
THE BROOKHAVEN AUTOMATIC SEQUENTIAL PRECIPITATION SAMPLER
}

\author{
Gilbert S. Raynor and John P. McNeil
}

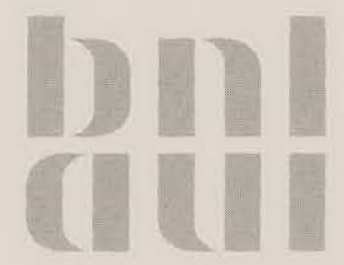

January 1978

ATMOSPHERIC SCIENCES DIVISION DEPARTMENT OF ENERGY AND ENVIRONMENT

BROOKHAVEN NATIONAL LABORATORY ASSOCIATED UNIVERSITIES, INC. UNDER CONTRACT NO. EY-76-C-02-0016 WITH THE UNITED STATES DEPARTMENT OF ENERGY 


\section{DISCLAIMER}

This report was prepared as an account of work sponsored by an agency of the United States Government. Neither the United States Government nor any agency Thereof, nor any of their employees, makes any warranty, express or implied, or assumes any legal liability or responsibility for the accuracy, completeness, or usefulness of any information, apparatus, product, or process disclosed, or represents that its use would not infringe privately owned rights. Reference herein to any specific commercial product, process, or service by trade name, trademark, manufacturer, or otherwise does not necessarily constitute or imply its endorsement, recommendation, or favoring by the United States Government or any agency thereof. The views and opinions of authors expressed herein do not necessarily state or reflect those of the United States Government or any agency thereof. 


\section{DISCLAIMER}

Portions of this document may be illegible in electronic image products. Images are produced from the best available original document. 
BNL 50818

UC-11

(Environmental Control Technology

and Earth Sciences - TID-4500)

\title{
THE BROOKHAVEN AUTOMATIC SEQUENTIAL PRECIPITATION SAMPLER
}

\author{
Gilbert S. Raynor and John P. McNeil
}

January 1978

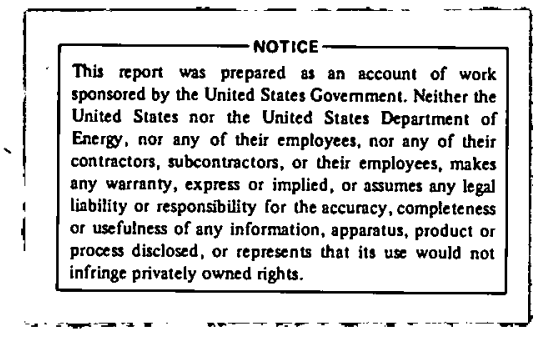

ATMOSPHERIC SCIENCES DIVISION

DEPARTMENT OF ENERGY AND ENVIRONMENT

BROOKHAVEN NATIONAL LABORATORY UPTON, NEW YORK 11973 
NOTICE

This report was prepared as an account of work sponsored by the United States Government. Neither the United States nor the United States Department of Energy (DOE), nor any of their employees, nor any of their contractors, subcontractors, or their employees, makes any warranty, express or implied, or assumes any legal liability or responsibility for the accuracy, completeness or usefulness of any information, apparatus, product or process disclosed, or represents that its use would not infringe privately owned rights.

Printed in the United States of America

Available from

National Technical Information Service

U.S. Department of Commerce

5285 Port Royal Road

Springfield, VA 22161

Price: Printed Copy $\$ 4.50$; Microfiche $\$ 3.00$

May 1978

365 copies 


\begin{abstract}
An Automatic Sequential Precipitation Sampler was designed and constructed at Brookhaven National Laboratory to collect precipitation samples for chemical analysis. The sampler is designed to collect both wet and frozen precipitation and to exclude dry fallout between precipitation events. The sampler consists of a large box containing a turntable holding 30 sampling bottles. Precipitation enters through a funnel on the top of the box. Between periods of precipitation, the funnel is closed by a movable cover which is actuated by a rain sensor when precipitation starts. Sample bottles are changed automatically and periodically from the time the cover opens. Times of cover opening and closing and of bottle changing are recorded on an event recorder. The sampler has operated successfully since June 1976.
\end{abstract}




\section{INTRODUCTION}

The recent increase of interest in precipitation chemistry, particularly in the "acid rain" problem in the Northeastern United States and Scandinavia, has created a need for new and improved methods of collecting precipitation samples for chemical analyses. Numerous devices have been used in the past for this purpose. The earliest were merely open containers such as rain gages which did not exclude dry fallout or deposition of particulate matter between precipitation events. Samples were usually removed either weekly or monthly but, in some cases, after each precipitation event.

The first improvement was the use of a cover and a precipitation sensing device so that the cover opened automatically when precipitation started and closed after it ended. Such devices were more complex and costly, subject to mechanical and electrical problems and required electrical power from either an AC line or a battery. Devices of this nature were described by Humphrey ${ }^{1}$, Volchok and Graveson ${ }^{2}$ and Battelle Pacific Northwest Laboratories $^{3}$. All have heated precipitation sensors which can be actuated by frozen precipitation. All exclude dry fallout. The first two can be operated on an event or on a longer period basis. The Battelle collector is designed for event use.

Several other single sample collecting devices have also been developed, and at least two are available commercially. Collectors of ten different designs were tested and their capabilities evaluated at Cornell University ${ }^{4}$. Additional studies of collector design were reported by Weibe 5 .

In recent years, several samplers have been developed which take sequential samples automatically. Gatz, et al. ${ }^{6}$ described a sampler operating on the principle of aftipping bucket rain gage which takes up to 70 samples 
and chaifis: collecting bottles on an amount basis. The duration of each sample varies with the rainfall rate and no provision is made for sampling frozen precipitation.

Gray, et al. $^{7}$ described a battery-powered portable sequential sampler designed for short sampling times and small samples. It operates on a time basis and has no provision for frozen precipitation. Neither the Gatz nor the Gray sampler exclude dry fallout.

Several other precipitation collectors are known to be in operation or under construction but these have not yet been reported in the literature.

\section{DESIGN CRITERIA}

For research studies at Brookhaven National Laboratory, a sampler was required that would incorporate the best features of previous collectors and include a number of other essential capabilities. Basic requirements were automatic, sequential sampling, exclusion of dry fallout and the ability to collect frozen precipitation. A decision was made to sample on a time rather than a volume basis so that analytical results could be related more readily to meteorological or other pertinent parameters. However, it was decided to make the time period manually variable.

Samples large enough for the desired chemical analyses (about $35 \mathrm{ml}$ ) at a rainfall rate of 0.01 inch $(0.25 \mathrm{~mm})$ per hour were desired with collection bottles large enough so that they would not fill up at any but extreme rainfall rates. If a bottle became full, however, it should be replaced automatically so that no sample would be lost. The sampler needed enough collection bottles so that time of bottle change could be flexible but it should shut off automatically if all bottles were used. The time and duration of 
each sample should be recorded. Because of the necessary size and complexity of the sampler and the small probability of using it in remote locations, it would operate on AC power. All of these criteria were successfully met in the device described below.

\section{DESCRIPTION}

The sampler body (Figure 1) is a box constructed of 0.125 inch aluminum plate on a welded frame of $2 \times 2 \times 0.25$ inch aluminum angle. The box is five feet square, 25 inches tall and mounted on.13-inch tall legs of the same aluminum angle. The sides of the box are removable for access to the interior. A 16-inch diameter stainless steel mixing bowl is used as a funnel and is located near a top corner of the box supported by a circular mount. A 30 foot heating tape (Automatic Ready Heat, Model ARD 30-110) is wrapped around the bottom side of the funnel supported by metal clips welded to the funnel. The volume between the funnel and its mount is filled with insulation to direct heat to the funnel surface. The heating tape is thermostatically controlled and operates at temperatures below about $2^{\circ} \mathrm{C}$ to melt frozen precipitation.

The funnel is covered with a movable cover in the absence of precipitation. The cover (Figure 2) is 18 inches square with a 6-inch high pitched roof on which are mounted two precipitation sensors (Figure 3 ). When the sensors are actuated by precipitation, the cover moves to a rest position behind the funnel, exposing the funnel to precipitation (Figure 4). Movement is accomplished by a Model NCI12RG, $3.6 \mathrm{rpm}, 1 / 70 \mathrm{hp}$, reversible Bodine motor with 52 inch-pounds of torque mounted inside the box. The motor operates a set of pivoted arms on either side of the cover (Figures 2 and 5). Each set consists of four segments with nylon bushings at the pivot points. A shear pin is located at one of the pivot points to prevent damage if the arms are 
immobilized due to freezing rain or other causes. When actuated, the cover takes 8 seconds to clear the funnel and 14 seconds to come to its rest position. Limit switches stop further travel after the open and closed positions are reached. The cover design is similar to that used in the wet/dry fallout collector (HASL collector). ${ }^{2}$

The precipitation sensors (Figure 3) are copies of those used in that collector also. They include stainless steel lower plates, 1-11/16 x 2-15/16 in., on somewhat larger insulating base plates and raised stainless steel upper plates, $3 \times 3-1 / 4$ in. The upper plates consist of an outer frame with eight 1/16-1nch parallel bars spaced $1 / 4$ inch apart crossing from side to side. The upper plate is separated from the lower plate by $3 / 32$-inch insulating spacers at the four corners. The separation distance must be crossed by a drop of water to actuate the sensors.

Small electric heaters (MINCO HR 5107 B 14.0) controlled by a thermostat (GV Model VE2101) are mounted below the sensors. The heaters are actuated whenever the hood is open in order to dry residual drops after precipitation ceases and whenever the air temperature falls below about $4^{\circ} \mathrm{C}$ to melt frozen precipitation.

A 56-inch diameter turntable, 3.5 inches high, holding 30 two-quart ( 1.9 1t.) polyethylene wide-mouth bottles, is mounted inside the box 7.5 inches above the floor (Figure 6). The turntable is mounted on a machine tool indexing plate (Allenair 11E A-30 position) normally air-operated but here operated by an eccentric cam driven by a Model NSI-33RJ, $3.2 \mathrm{rpm}$, $1 / 20 \mathrm{hp}$, split-phase Bodine motor. The turntable steps or indexes $12^{\circ}$ each time it is actuated and takes 16 seconds to move from one position to the next. The sampler is normally operated on a one-hour time cycle but can be 
operated on any time cycle up to 99 minutes by manually changing the elapsed time thumbwheel switches. Shorter time cycles such as 5 minutes may be used when sampling heavy thunderstorm precipitation.

From the base of the funnel, water flows through a short length of stainless steel pipe sloped to prevent water accumulation and through a 3/4inch solenoid valve before falling into the bottle in collecting position. The solenoid valve (ASCO 8030B83) closes automatically during the periods of bottle changing to prevent loss of sample and to prevent water from wetting the inside of the sampler box. Below the solenoid valve is an overflow sensor consisting of a housing containing a GE 1815 miniature bayonet base light source and a Clairex CL 603 photocell. These are mounted in collimated tubes aimed at a point about one inch below the top of the bottle in collecting position (Figure 6). If the water level reaches that height, light from the bulb is reflected from the water surface to the photocell actuating a circuit which steps the turntable to the next position. This does not change the basic time cycle but gives two samples rather than one within that hour.

The sampler is mounted outside the meteorology building near the rain gages and instrument shelter. A display and control panel (F1gure 7) is mounted inside the building and connected to the sampler by electrical cables. The display indicates the time cycle, the cover position and, if open, the number of samples previously collected, the elapsed time since the current sample started and the number of overflow samples. The panel contains reset buttons to reset the latter two displays and their circuits to zero after precipitation has ceased and samples have been removed from the sampler.

One pen of an Esterline Angus event recorder located below the display panel moves to the energized position whenever the cover is open (Figure 8). 
Another pen gives a mark each time the turntable operates to change a sample. Thus, the time of beginning and end of each sample and the duration the cover is open, if less than the full hour, are recorded to the nearest minute. Another pen on the same recorder is operated by a tipping bucket rain gage so that the amount of rain during each sample is recorded to the nearest 0.01 inch. Since the tipping bucket gage is inoperative during freezing or frozen precipitation, an adjacent weighing rain gage is used to give amounts of such precipitation.

\section{ELECIRICAL CIRCUITS}

A block diagram of the electrical circuits is shown in Figure 9 . When shorted by a drop of rain, the precipitation sensor circuit actuates the precipitation collector control circuit which starts the timing section in the logic and control circuit. Interconnections between sub-circuits are indicated by arrows which show the direction of information flow. Final outputs include the LED (light emitting diode) displays and the event recorder which is actuated through the event recorder control circuit.

\section{Precipitation sensor circuit}

Details of the precipitation sensor circuit (Figure 10) which is located in the cover of the sampler follow those given by Volchok and Graveson ${ }^{2}$.

Precipitation falling on the sensor shorts the grid which turns on transistor TR1. This then turns on TR2 while TR3 remains open. When TR2 is on, its collector becomes more positive, thus firing the silicon controlled rectifier (SCR) D1. This allows current to pass through the wet stop microswitch SW1 which is operated in the normally open condition to energize relay $\mathrm{K} 1$. A $110-\mathrm{V}$ AC signal then passes through the relay contacts to energize the cover motor to open the cover. 
When the cover reaches its open position, a cam on the motor shaft deenergizes SW1, stopping the motor. SW2 is then energized setting the path for current to flow to relay K2 to close the cover when (SCR) D2 is fired. Opening of the cover also energizes the heaters below the precipitation sensors. The heaters are also thermostatically controlled to operate at temperatures below about $2^{\circ} \mathrm{C}$.

When the precipitation sensor dries off, both TR1 and TR2 are turned off. With TR2 off, its collector becomes more negative, turning off (SCR) D1. With TR2 collector negative, TR3 turns on allowing its collector to become more positive, firing (SCR) D2. This then energizes relay K2 through SW2 which energizes the cover motor in the reverse direction. When the cover reaches its closed position, the cam on the motor shaft opens SW2 which deenergizes the motor. Meanwhile SW1 will close which prepares the circuitry for the next precipitation event.

Precipitation sampler control circuit

The precipitation sampler control circuit (Figure 11) includes the overflow circuit and interconnections between the precipitation sensor circuit and the logic and control circuit. It is physically located in the precipitation sampler body as are relays $\mathrm{K} 1$ and $\mathrm{K} 2$ described above.

When 30 samples have been taken, the logic circuit actuates relay $\mathrm{K} 3$ which puts a voltage signal of opposite polarity on the base of TRI (Fig. 10). This causes the cover to close, and shuts down the system even though the precipitation sensors may still be wet.

After the elapsed time of a sample bottle exposure equals the predetermined time set on the thumbwheel switch in the timing circuit, relay $\mathrm{K} 4$ is energized allowing current to flow through the relay contacts to the indexing motor. This motor rotates $360^{\circ}$ but is geared to turn the turntable 
only 12 degrees. At the end of this travel, a cam on the motor shaft engages reset microswitch SW 3 (Figure 10) which stops the motor and sends a signal to the logic and control circuit. This signal resets the elapsed time counter, advances the total sample counter, and actuates the sample pen on the event recorder.

PCl is a printed circuit card which contains a comparator circuit which may be actuated by the overflow circuit. When the voltage passing through the Clairex photocell reaches a reference voltage, the logic and control circuit initiates the indexing operation described above, actuates the sample pen on the event recorder, advances the sample counter but does not interrupt or reset the timing circuit.

Logic and control circuit

The logic and control circuit is shown in Figure 12, $A, B$ and $C$, and includes the functions shown in outline form in Figure 9. It is located with the display and control panel in the building. This circuit accepts input signals from the circuits previously described, controls the sequence of events in the entire sampler and sends output signals to the LED displays and to the event recorder through the event recorder control circuit described below. The logic and control circuit includes the clock section, the logic area, the overflow circuit and the output section.

The clock circuit (IC 15,16 and 17) (Figure 12B) produces either a one second or a one minute pulse depending on the setting of toggle switch SW5 (Figure 12B). The selected pulse passes through the pulse selector circuit (IC6) to activate the elapsed time counter through gate IC1, pins 4,5 and 6 (Figure 12B) to IC21, pin 14 (Figure 12C). The clock pulses are applied to IC21 through one gate of the four-gate ICl. Two of the gates are used as a set-reset flip-flop which serves two purposes: (1) to control the clock pulse to IC21 in accordance with the position of pin 1 of IC5 (Figure 12A) and the 
thumbwheel switches SW7 and SW8 (Figure 12C) and; (2) to energize relay IC29 through one gate of IC3, IC7 and IC9 at the proper time (Figure 12B).

The logic area includes photo-transistors (opto-isolator MCT-2, IC11-13) (Figure 12A) which receive the appropriate voltage signal from the precipitation sampler control circuit. When ICll receives a signal that the cover has been opened, IC1, pin 4 (Figure 12B) allows the clock pulses from the pulse selector circuit to pass and increment the elapsed time counter (IC21, IC22) (Figure 12C) starting the counting sequence. IC12 (Figure 12A) receives a voltage signal when microswitch SW3 (Figure 10) has made a closure. This is the reset signal that sets the elapsed time counter (IC21, IC22) to zero and advances the sample taken counter (IC19) (Figure 12A) by one digit.

When IC13 (Figure 12A) receives an overflow signal from PC1 (Figure 11) IC29 is energized through IC7 (Figure 12B). IC14 is a one-minute time delay preventing IC5 output pin 1 (Figure 12A) from resetting the elapsed time counter (IC21, IC22) (Figure 12C) even though IC12 (Figure 12A) receives a reset signal.

IC18-22 (Figures $12 \mathrm{~A}$ and $12 \mathrm{C}$ ) are decade counters that drive conventional seven-segment decoders (IC23-27)(Figures $12 \mathrm{~A}$ and $12 \mathrm{C}$ ) and associated readouts DS 1 to DS5 (Figure 12C). IC3 (Figure 12A) is used as a contact board circuit to prevent transient pulses from triggering the circuit when a manual pushbutton switch is pushed. IC29-31 (Figure 12B) are relay chips that make closures to control the indicated output functions.

Event recorder cont rol circuit

The event recorder control circuit (Figure 13) located near the event recorder in the building is merely a relay interface between voltage signals from the logic and control circuit and the event recorder. The coils of relays $\mathrm{K} 1$ and $\mathrm{K} 2$ are actuated by 12 volts while the contacts pass $110-\mathrm{V}$ AC to the event recorder pen coils. 


\section{Wiring}

Diagrams of actual wiring between components, location of wires on terminal strips and in plug connections are not included in the circuits shown but are available on request of anyone wishing to duplicate the sampler.

\section{OPERATION}

Prior to a precipitation event, one sampling bottle is located beneath the funnel, the cover is closed and all electrical clrcults are inoperative except for the one-second timing pulse. A drop of water large enough to cross the two conducting plates of a precipitation sensor actuates the electronic circuits which cause the cover to open, start the timing circuit and actuate the cover position pen on the event recorder. If precipitation stops and the sensor dries within the selected sampling period, the cover will close and the cover position pen on the event recorder will return to its unenergized position but the timing will continue to the end of the period. At that time, the turntable will be actuated moving the next bottle into sampling position and briefly actuating the sample change pen on the event recorder after which the timing will cease.

If the cover is still open at the end of the period, the next bottle will move into position, the sample change pen will record the move on the event recorder chart and the timing will continue. This process will be repeated until the cover closes or all thirty bottles have been used. If this occurs, the timing will cease and the cover will close to prevent additional exposure of bottles previously exposed to precipitation. If one bottle becomes full, the overflow circuit will cause a step to the next bottle without interrupting the basic one-hour timing sequence. Thus, the sample for that period will be collected in two bottles rather than one. 
Exposed bottles are normally removed at the end of each precipitation event or daily if precipitation continues. All bottles are carefully washed with distilled water before being placed in the sampler. The funnel and tubing are washed twice with distilled water after each precipitation event. The precipitation sensors are cleaned periodically. If more than a week or two elapses without precipitation, the funnel is washed and the washing analyzed. Pure distilled water is also poured into one or two unexposed bottles to determine if any dust penetrated into the sampler body. No significant amounts of contamination have been found in either test.

Water samples from the two-quart bottles are poured into numbered $500 \mathrm{~m} 1$ polyethylene bottles with screw caps. Amounts greater than $500 \mathrm{ml}$ are discarded. These samples are then taken to the laboratory for analyses. The pH and conductivity $(\mu m h o s / \mathrm{cm}$ ) are measured as soon as possible after the samples come to the room temperature at which the $\mathrm{pH}$ meter is calibrated. Samples are also analyzed for concentrations (ppm) of sulfate, nitrate plus nitrite, ammonium, sodium and chloride. If these measurements are not made immediately, samples are stored in a refrigerator. Details of the analytical methods will. be presented elsewhere.

During some periods, amounts of water collected are too small for any measurements to be made. The minimum useful sample is one large enough for a $\mathrm{pH}$ measurement and consists of about $10 \mathrm{~m} 1$. About $35 \mathrm{ml}$ are needed for all measurements. A rainfall of 0.01 inch gives a calculated sample of $33 \mathrm{~m} 1$ but losses in the funnel and tubing make the actual sample slightly less. Thus, somewhat over 0.01 inch of precipitation in a sampling period is necessary for all measurements. 
The sampler was put into operation in early June 1976 and collected over 600 samples large enough for at least some analyses during its first year of operation. It operated successfully through several snowstorms with air temperatures as low as $-5^{\circ} \mathrm{C}$. Only three types of problems have been experienced to date. On three occasions, nearby lightning strikes caused surges on the power lines which damaged either transistors or a power transformer. During the first winter, the heating coil under the funnel shorted out so that snow from one snowstorm and part of another failed to melt and run into the bottles as it fell. The coil was replaced by a heavier duty type. Loss of electrical power during Hurricane Belle in August 1976 kept one bottle in collecting position for several hours and some sample was lost when the bottle overflowed. However, the timing circuit resumed correct operation after power was restored.

\section{DATA}

All data are tabulated on input sheets from which cards are punched. The data are then transferred to magnetic tape for analysis by computer. Precipitation data recorded include station, date, precipitation event number during the month, sample number during the event, time of beginning and end of each sample, duration of each sample and amount of rainfall during each sample.

Chemical data recorded are $\mathrm{pH}$, conductivity and concentrations of total nitrogen, ammonium, sulfate, sodium and chloride ions. Meteorological data include precipitation type, cloud type, synoptic situation causing the precipitation, wind direction and speed at $108 \mathrm{~m}$ on a nearby meteorology tower and air temperature. Storm trajectories will be determined later from appropriate surface and upper air data and added to the data base. 


\section{DATA ANALYSIS}

Statistical analyses have been performed to determine the mean and variability of precipitation characteristics by event, month, season and year and to relate concentrations of selected chemical constituents to concentrations of other constituents. The data were also classified and analyzed by meteorological parameters such as precipitation type, precipitation rate, synoptic situation, wind direction and temperature. The data were also related to other measures of air pollution.

Differences between early and later samples during each precipitation event are being analyzed in an attempt to ascertain the mechanism by which the materials are incorporated into the precipitation. Materials incorporated during the cloud formation process (rainout) should be in reasonably uniform concentrations throughout the event while materials removed from the atmosphere below cloud level (washout) should be found predominantly in the early samples.

Attempts will be made to determine source regions of pollutants found in the precipitation by trajectory analysis, use of concentrations and ratios of constituents, and use of data on known emissions from major source regions.

The data will also be related to observed vegetational damage by specific rain events as part of a more comprehensive study of the effects of acid rain on vegetation. They will also be used as a guide in the preparation of simulated acid rain for use in laboratory exposures of vegetation to acid rain.

\section{ACKNOWLEDGEMENTS}

Robert Dillingham assisted in the design and supervised the construction of the mechanical portion of the sampler. Chemical analyses are being performed by the Analytical Chemistry Group of the Department of Energy and Environment under the supervision of Leonard Newman. 


\section{REFERENCES}

1. Humphrey, P. A., Automatic precipitation collector. Pres. 191st Nat. Meeting of Amer. Meteorol. Soc., March 21-23, 1961, Chicago, Ill.

2. Volchok, H. L. and Graveson, R. T., Wet/Dry fallout collection. Proc. Second Federal Conf. on the Great Lakes, Great Lakes Basin Commission, 1976, pp. 259-264.

3. Battelle Pacific Northwest Laboratories, The MAP3S Precipitation Chemistry Network: First periodic summary report (September 1976 June 1977), Report PNL-2402, Batte1le Pacific Northwest Laboratories, Rich land, Wash., 173 pp. (1977).

4. Likens, G. E., Peaka11, D. B., Galloway, J., Edgerton, E. and Ryan, M., Calibration of collection procedures for the determination of precipitation chemistry. Final report to Air Resources Laboratory NOAA. Cornel1 University, Ithaca, New York, 1975.

5. Weibe, H. A., The effect of precipitation collector design on the measured acid content of precipitation. Proc. First International Symposium on Acid Precipitation and the Forest Ecosystem, May 12-15, 1975, Columbus, Ohio. Report NE-23, U. S. Forest Service, Upper Darby, Pa., p. 135 (1976).

6. Gatz, D. F., Selman, R. F., Langs, R. K. and Holtzman, R. B., An automatic sequential rain sampler. J. Appl. Meteorol. 10, 341-344 (1971).

7. Gray, J., Hage, K. D. and Mary, H. W., An automatic sequential rainfal1 sampler. Rev. Sci. Instr. 45, 1517-1519 (1974). 


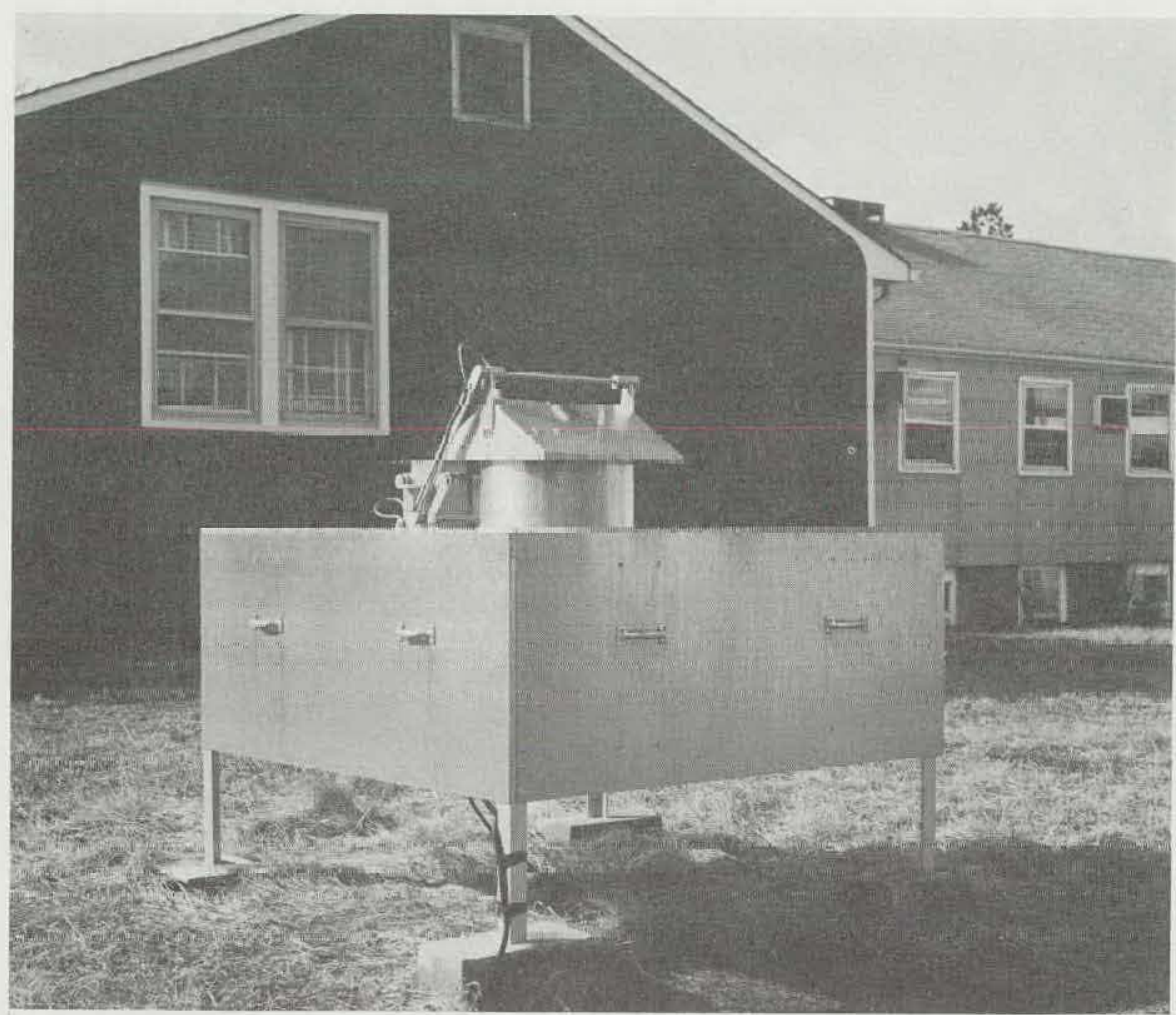

Figure 1. View of Brookhaven Automatic Sequential Precipitation Sampler with cover closed.

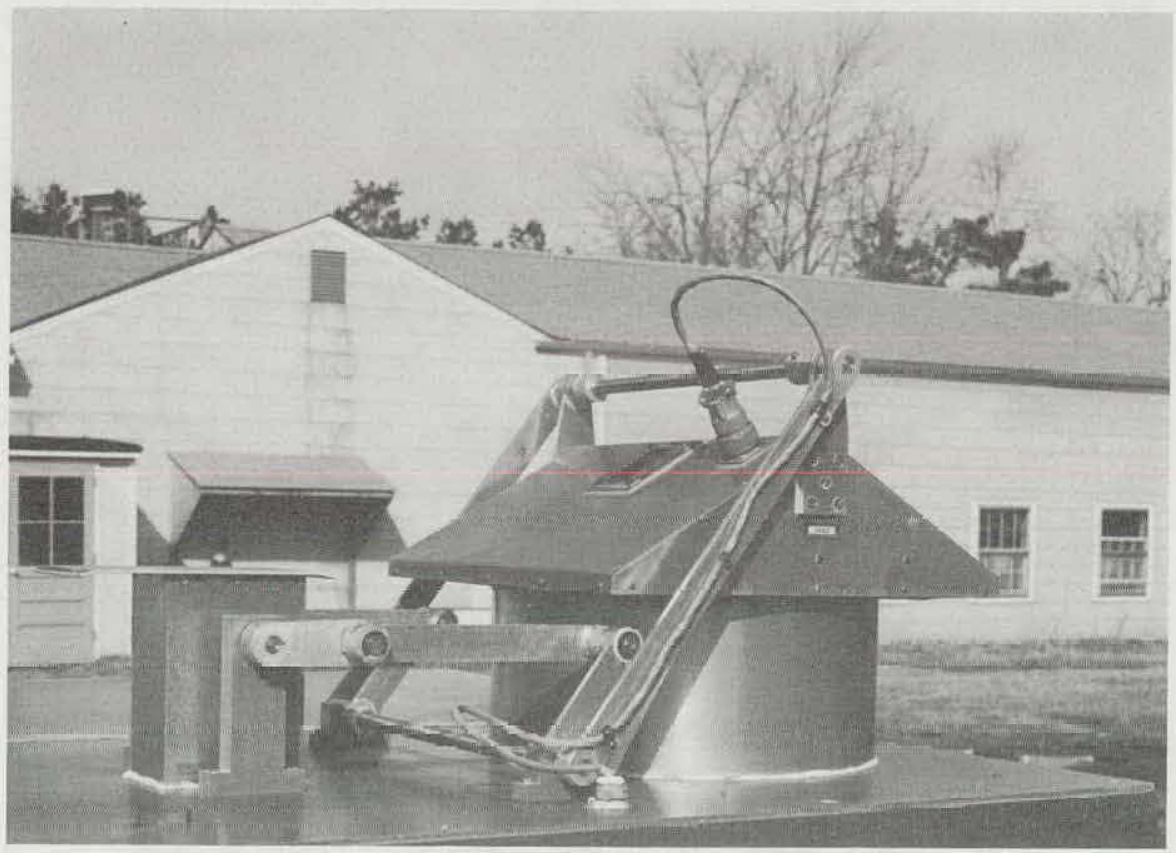

Figure 2. Close-up view of cover and actuating arms. 


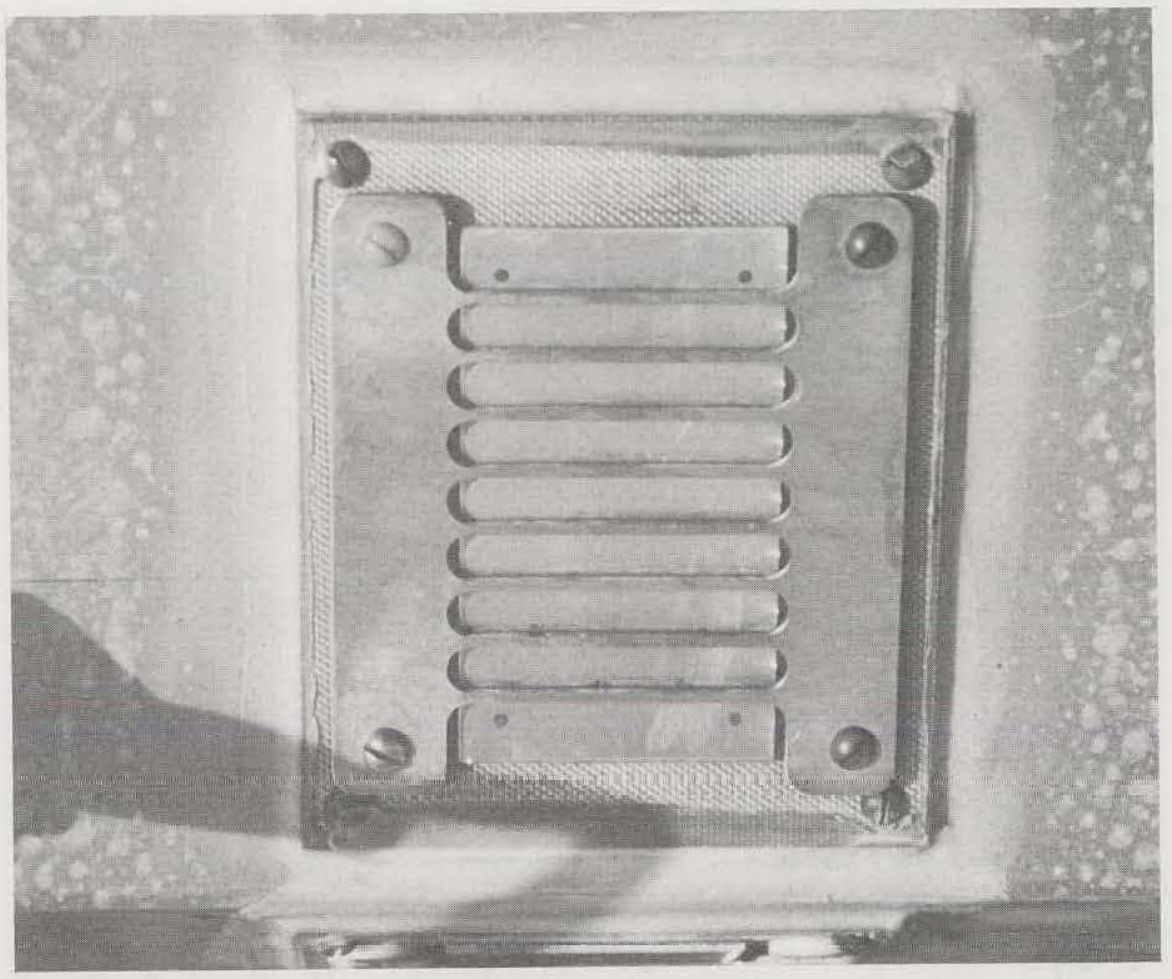

Figure 3. Close-up view of precipitation sensor.

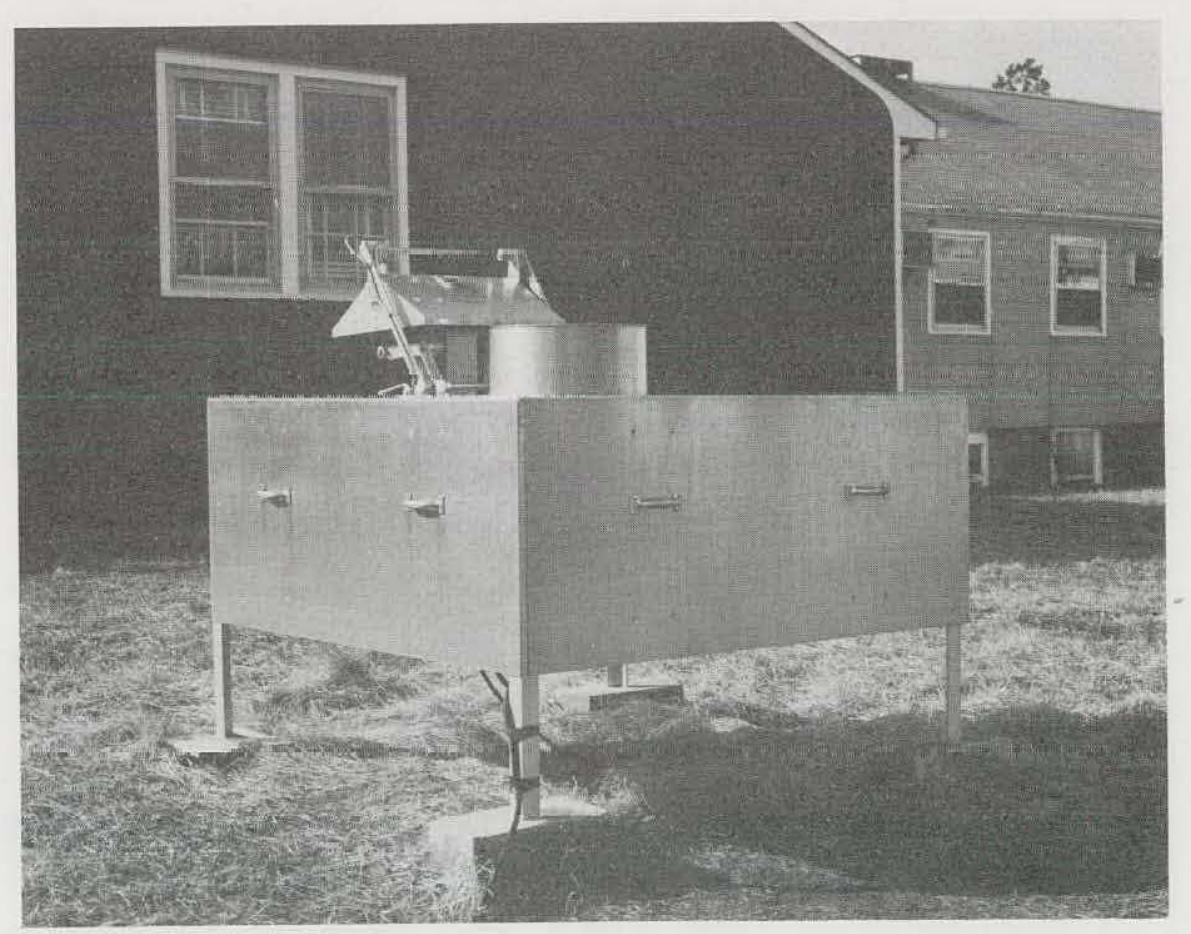

Figure 4. View of sampler with cover open. 


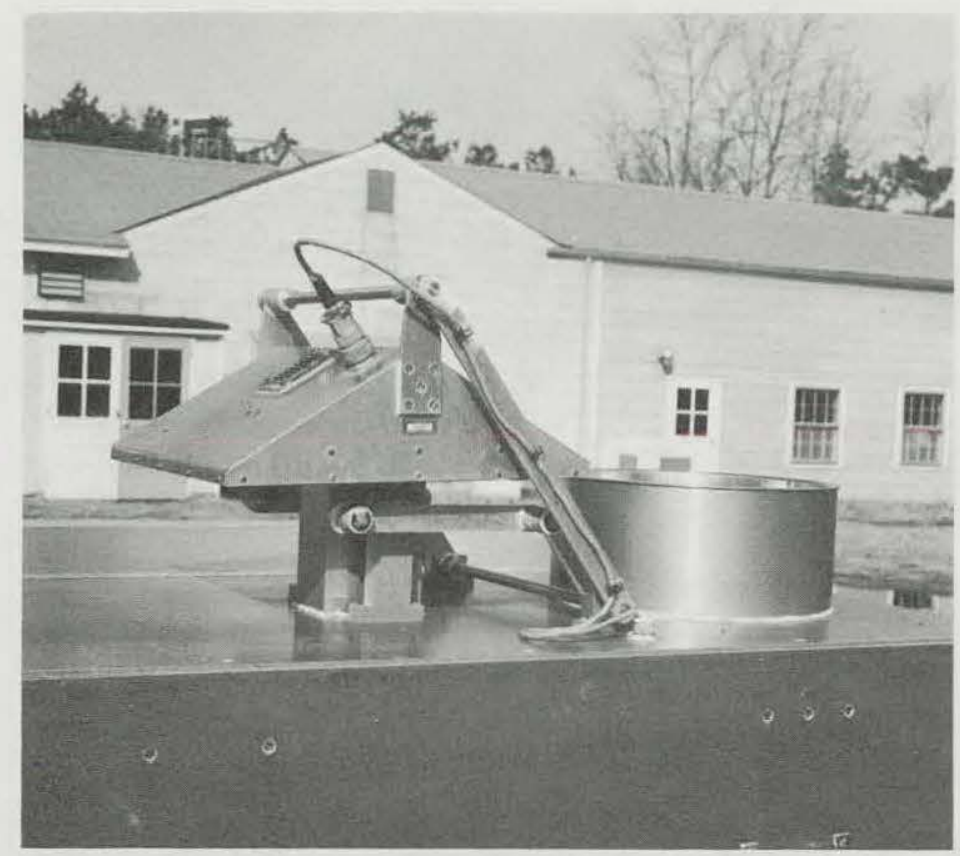

Figure 5. Close-up view of cover in open position.

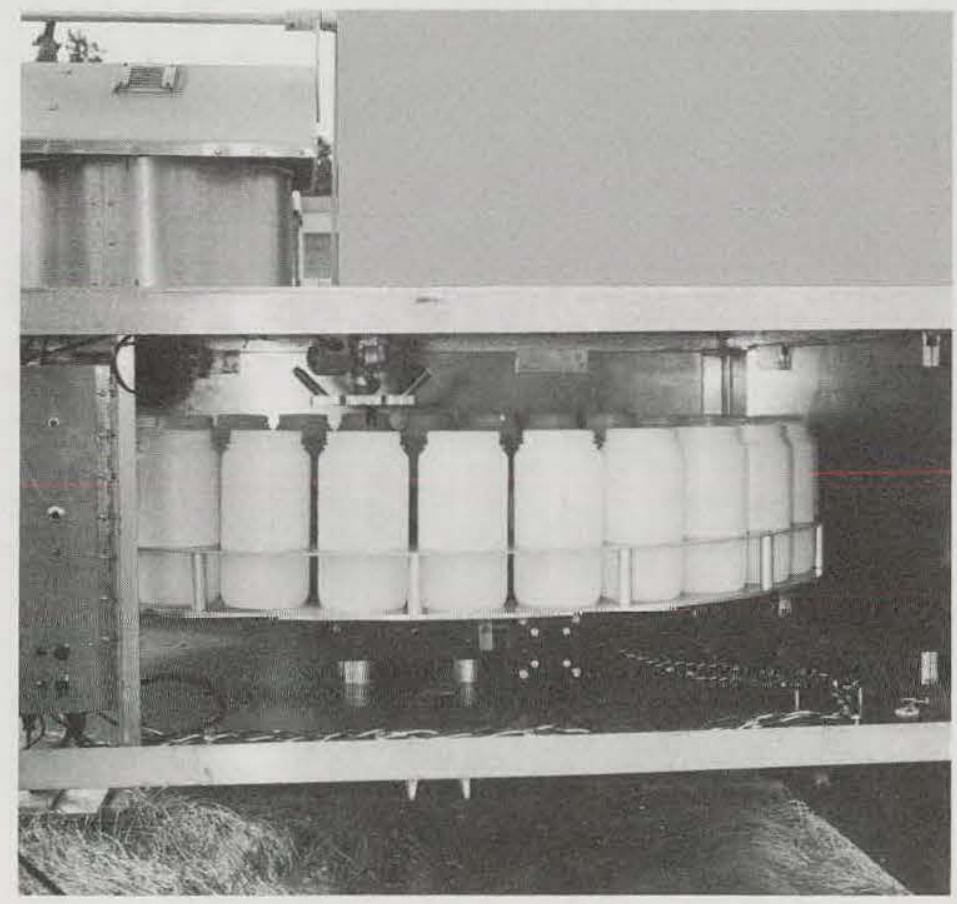

Figure 6. View of sampler interior showing turntable, collecting bottles and overflow sensing unit. 


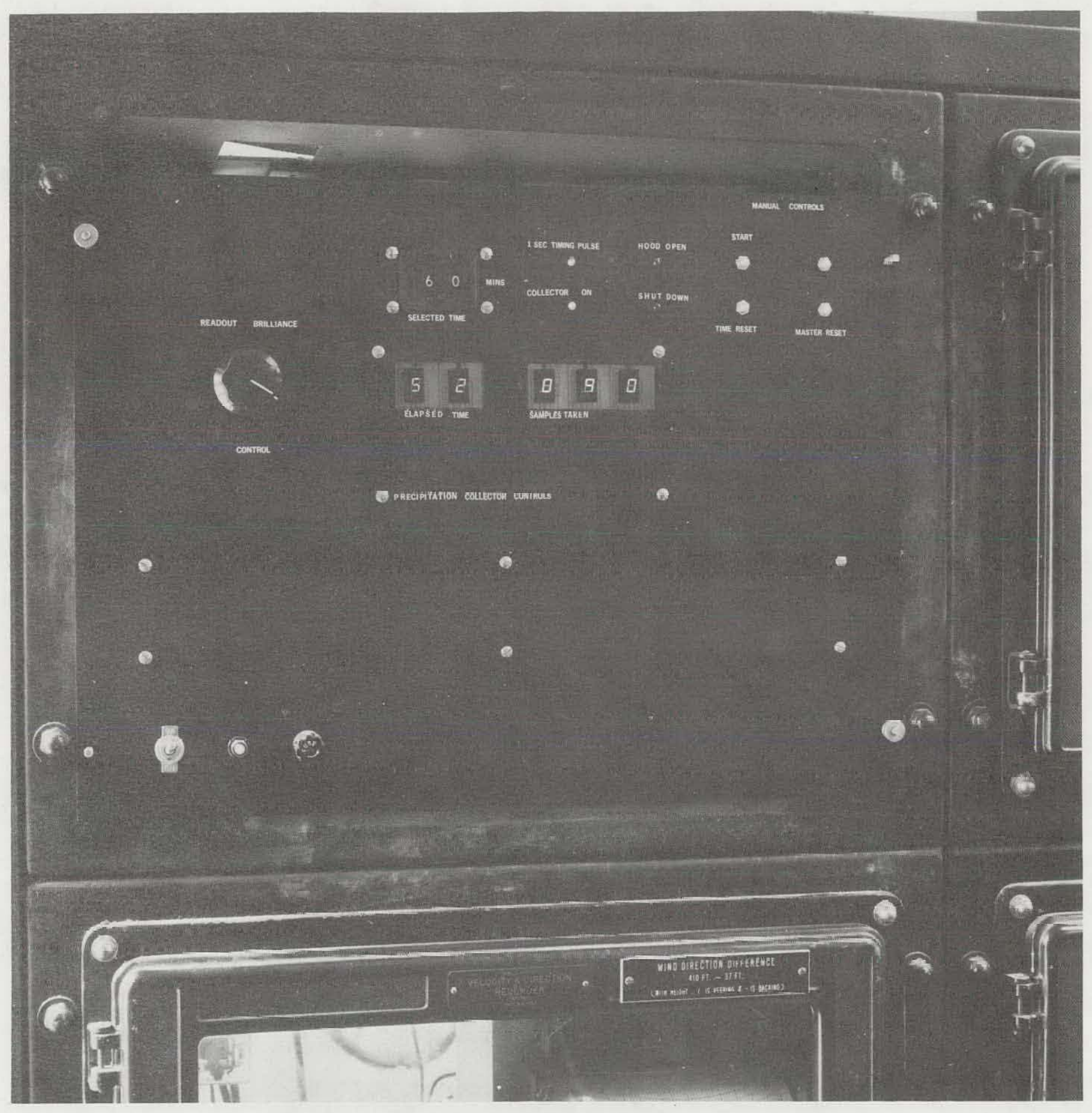

Figure 7. Display and control panel. 


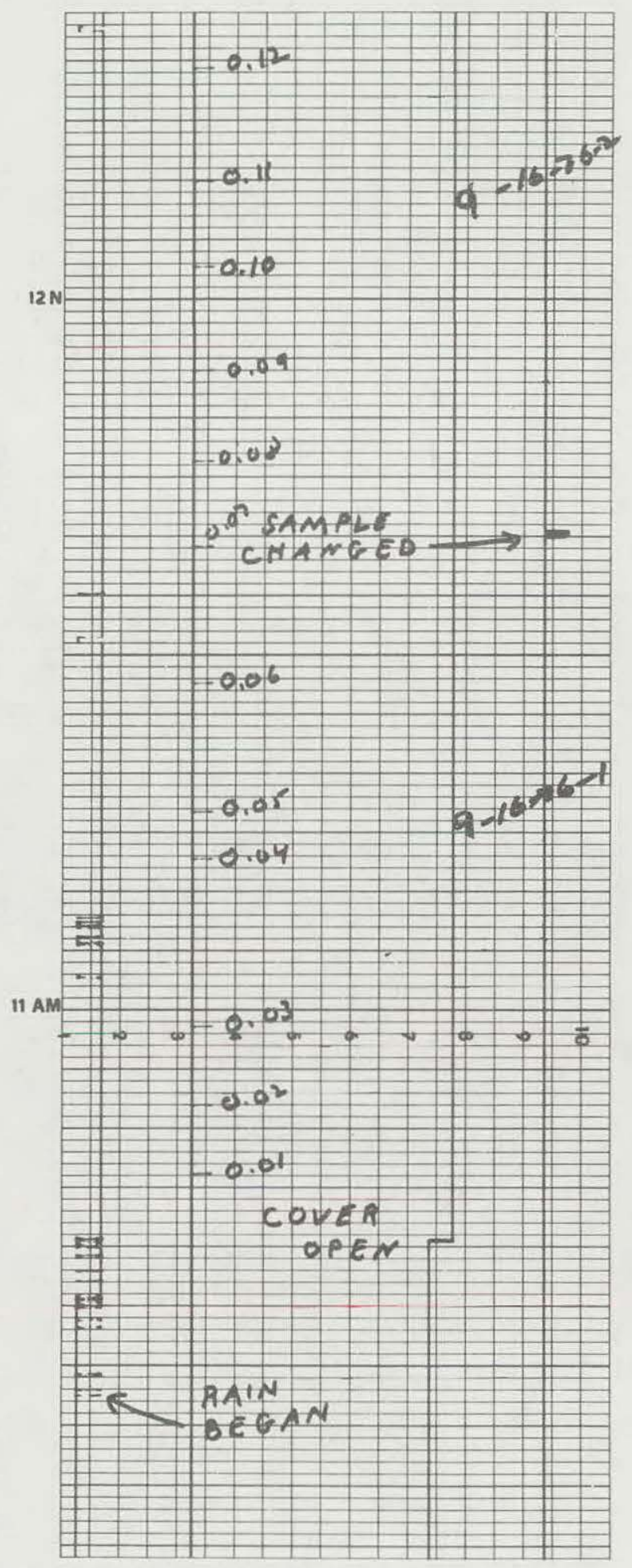

Figure 8. Representative chart record from event recorder showing t1me of cover opening, time of sample bottle change and rainfall from tipping bucket rain page. 
FLOW DIAGRAM

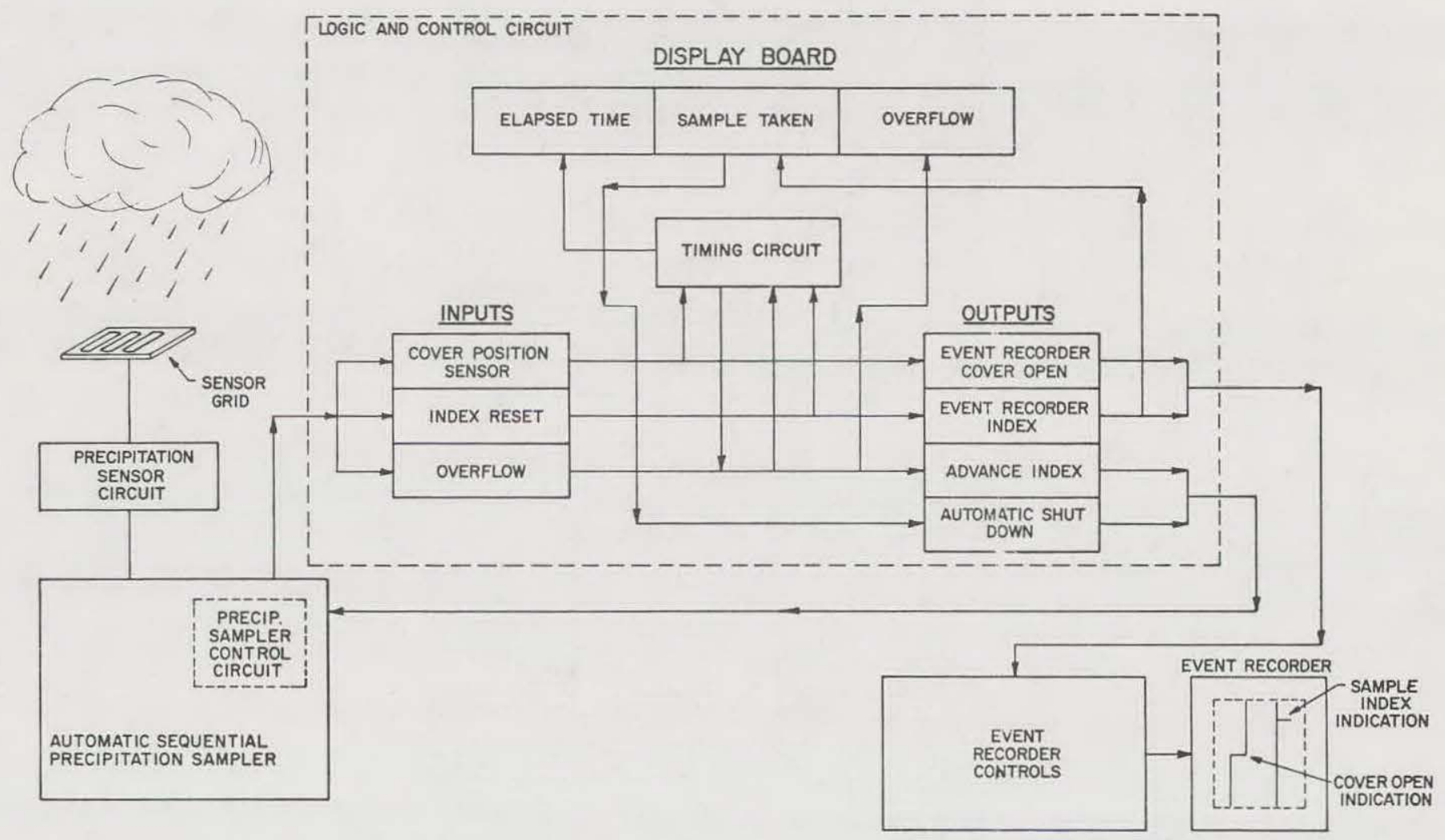

Figure 9. Block and flow diagram of electrical components and circuits. 


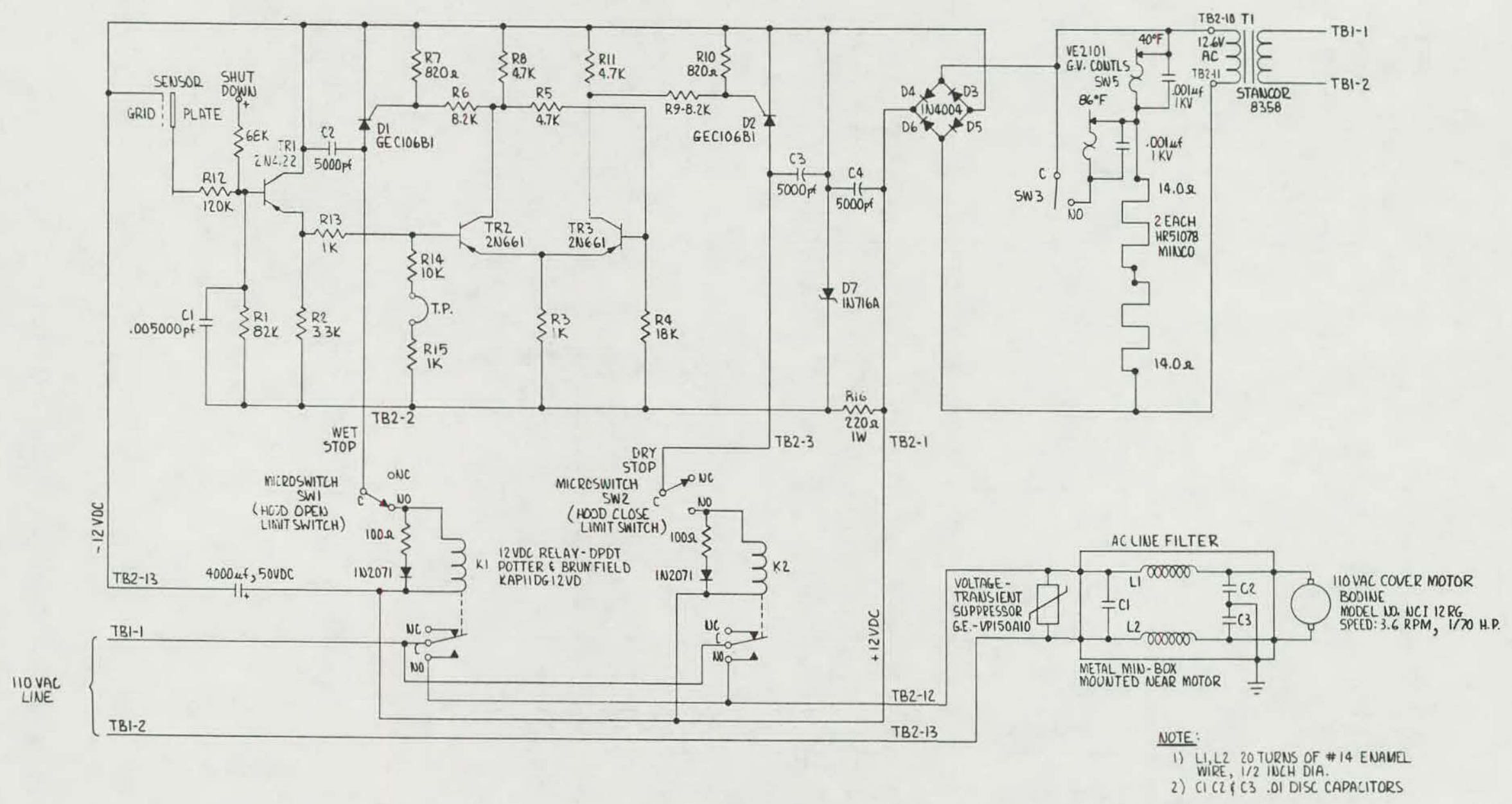

Figure 10. Diagram of precipitation sensor circuit. 


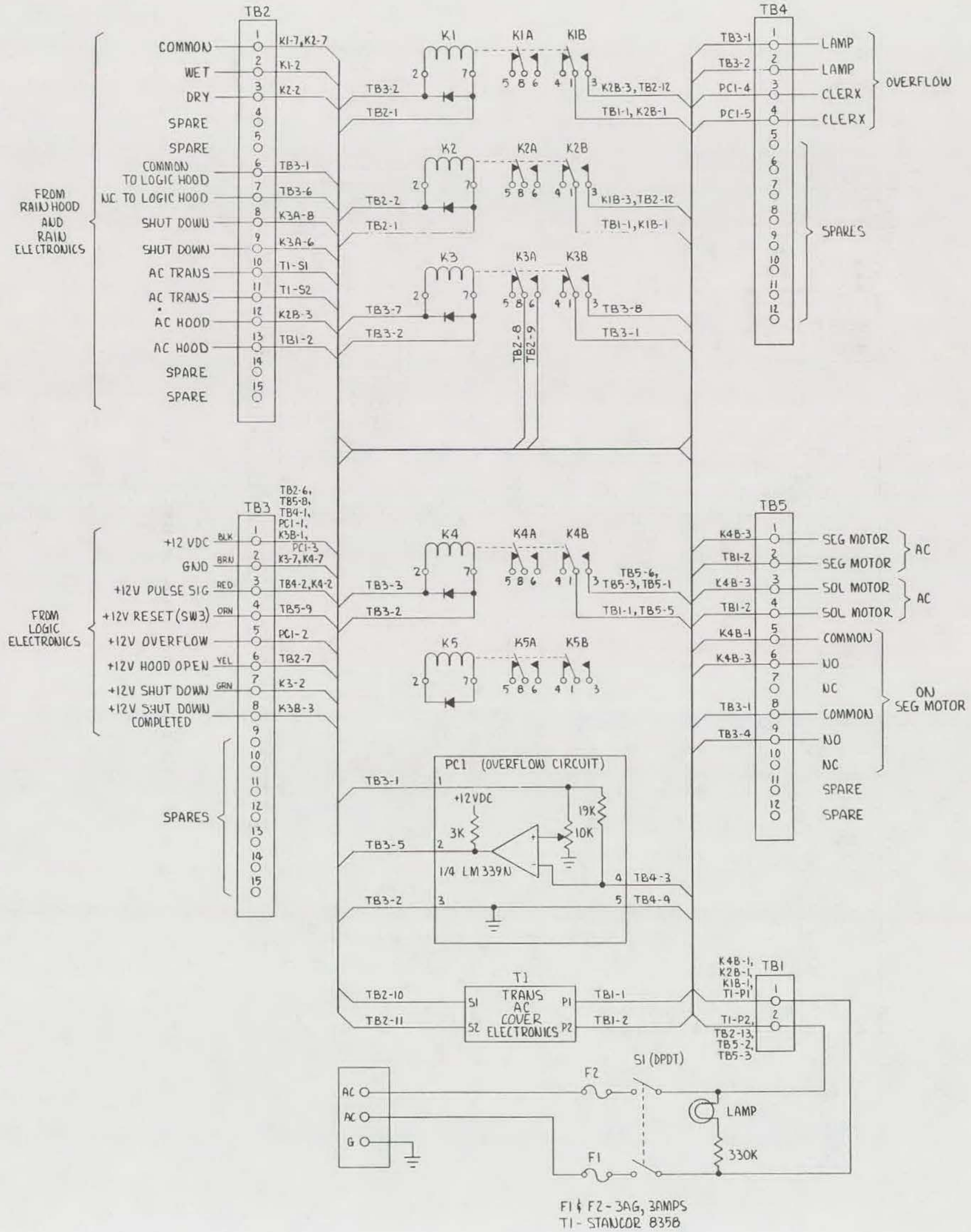

Figure 11. Diagram of precipitation sampler control circuit. 


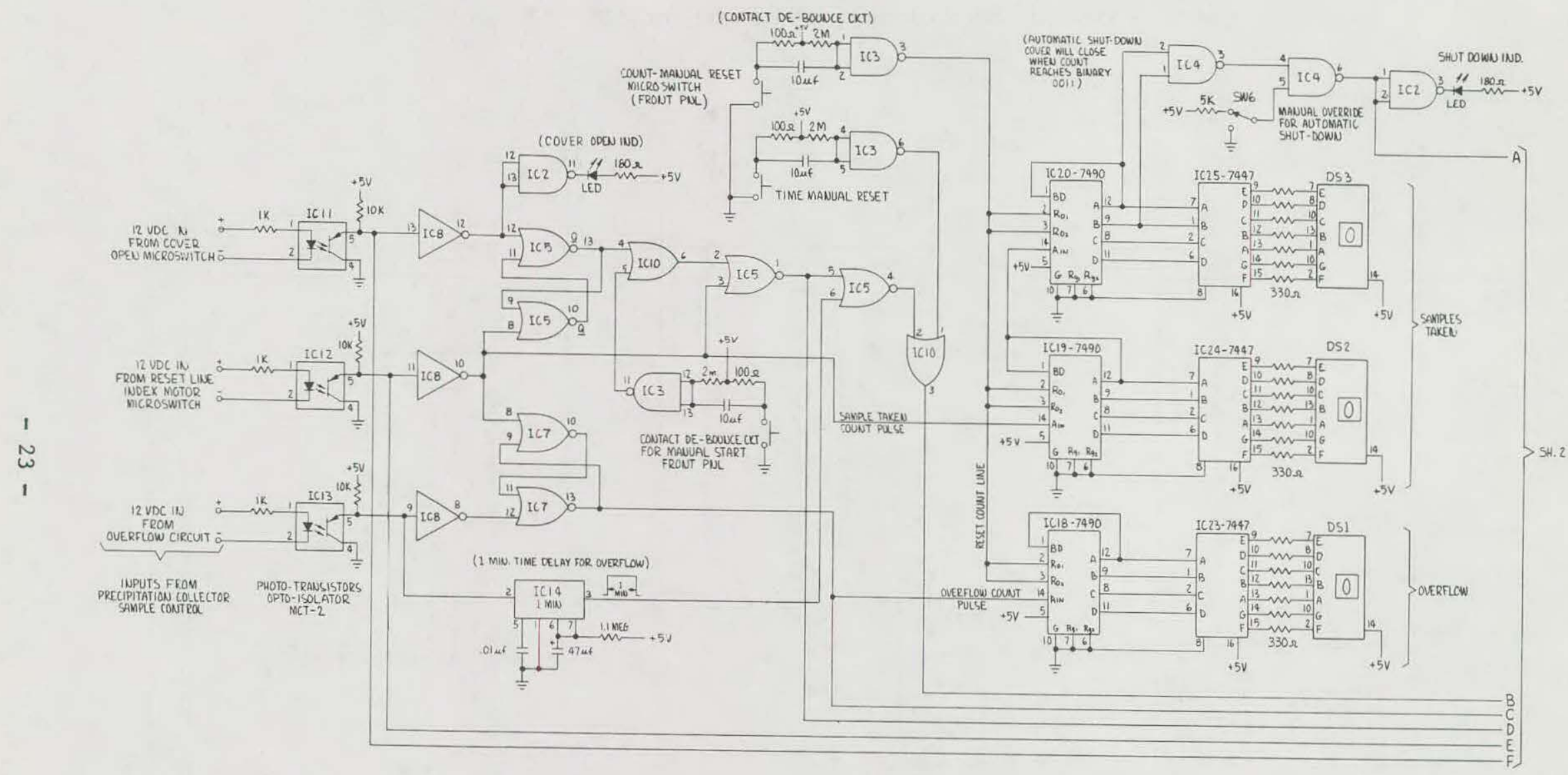

Figure 12A. Diagram of 10 ic and control circuit, Part A. 


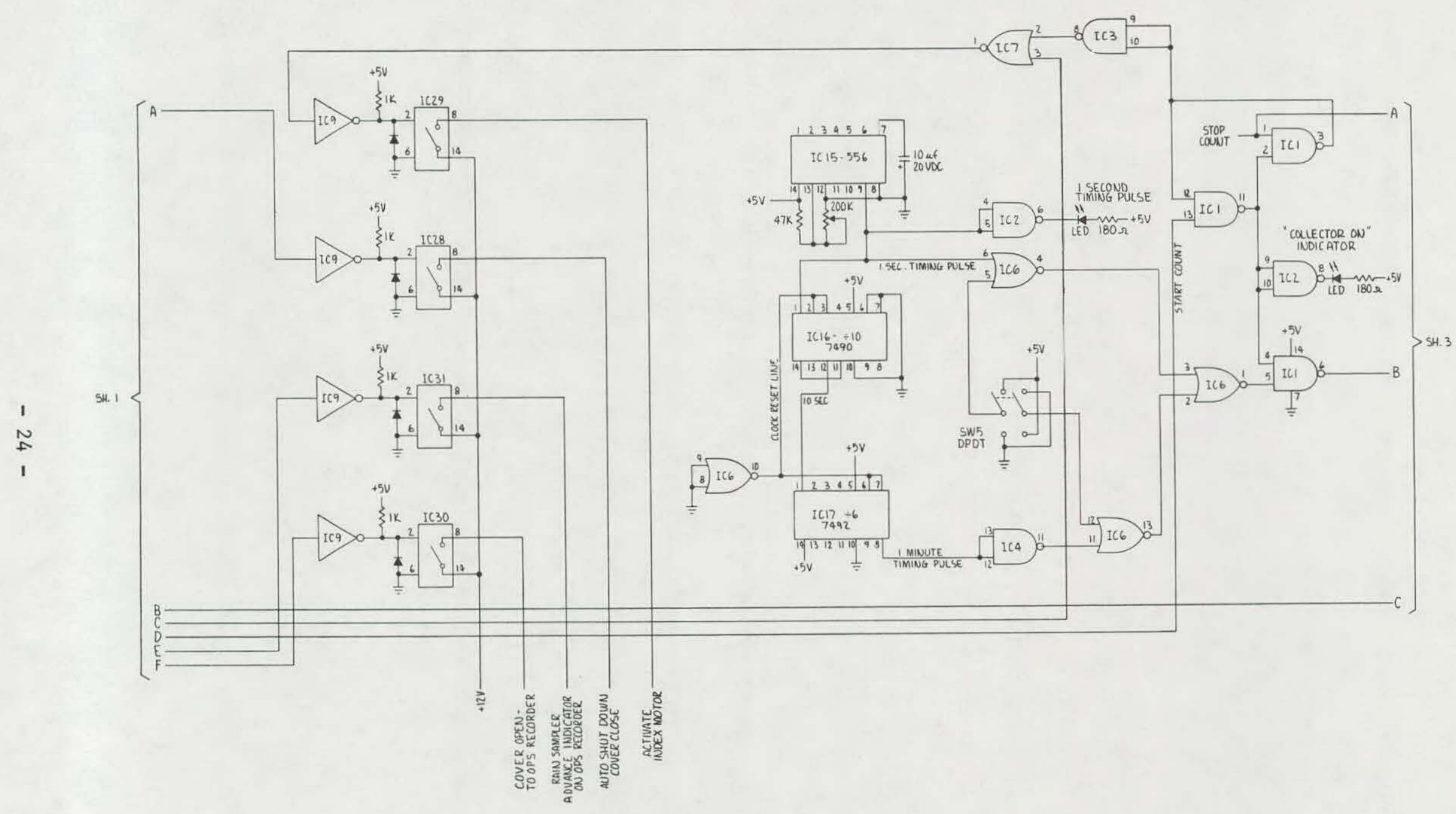

Figure 12B. Diagram of logic and control circuit, Part B. 


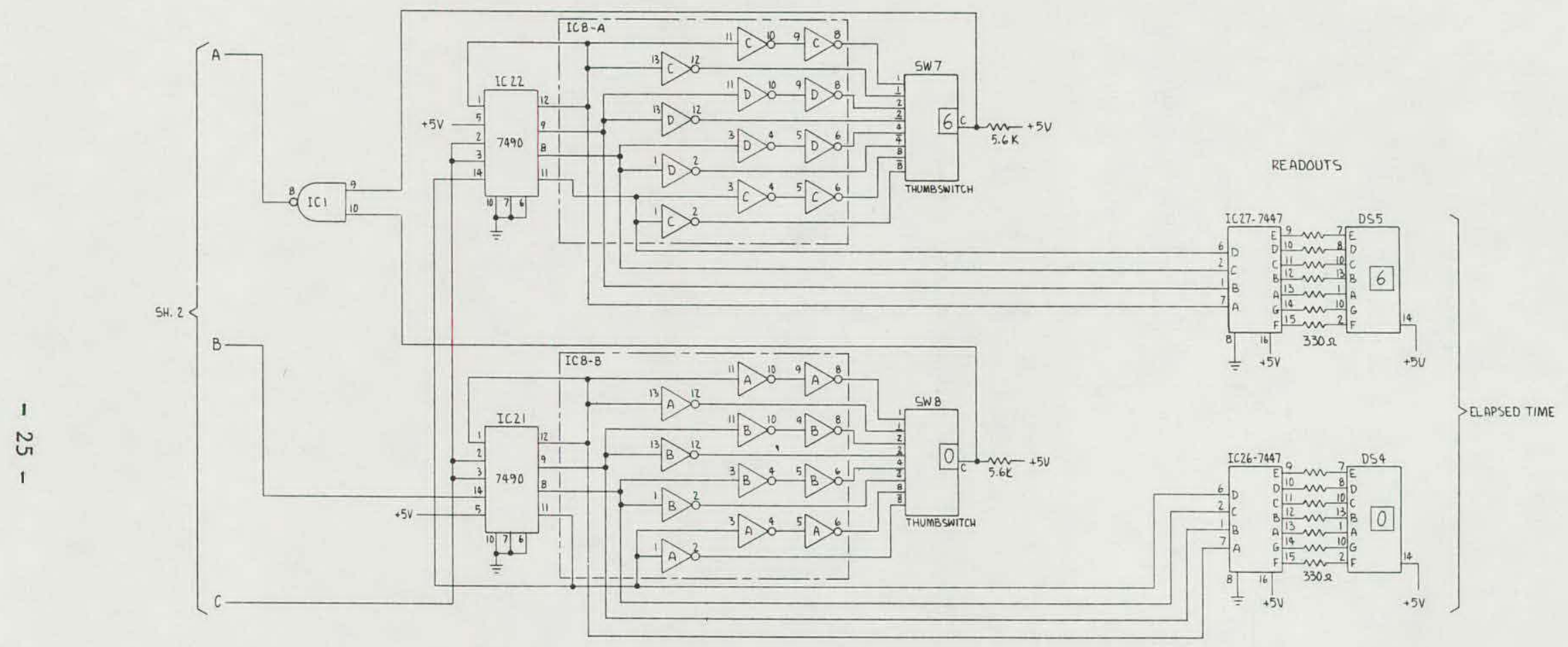

Figure 12C. Diagram of logic and control circuit, Part C. 


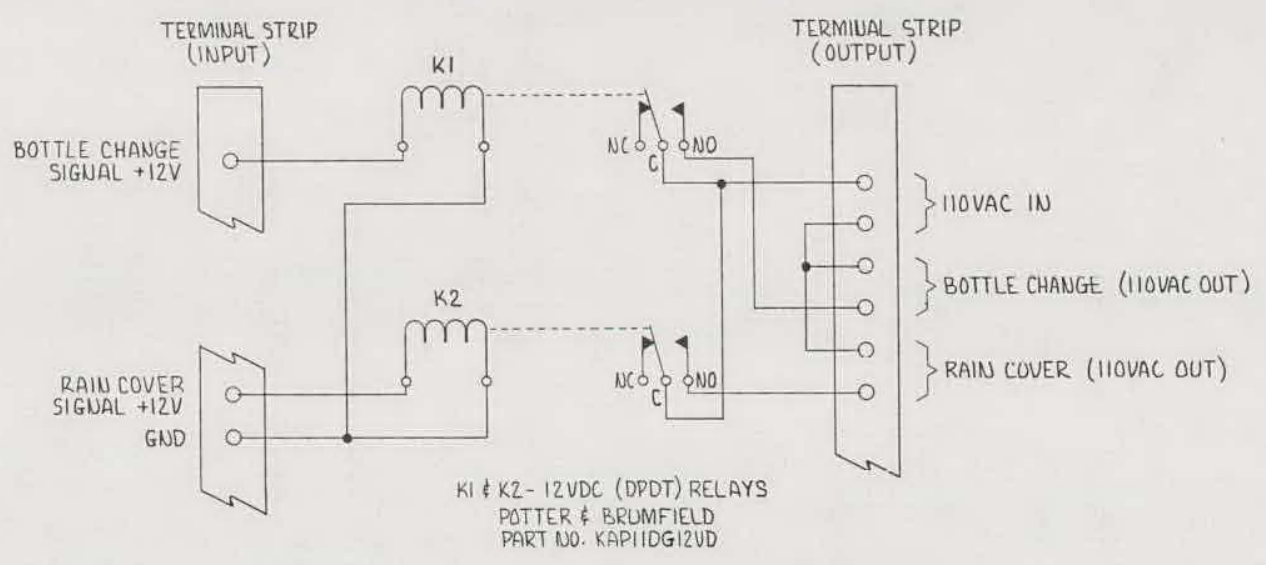

Figure 13. Diagram of event recorder control circuit. 